\title{
Amor, docência e Hannah Arendt: um diálogo proposto no/pelo mundo1
}

\begin{abstract}
RESUMO: Este ensaio tece considerações a respeito do conceito de amor mundi, conforme sugerido por Hanna Arendt, e a formação docente. O desafio proposto se coloca em, através do amor, propor um diálogo no(do) mundo com a educação, anunciando sentidos, sem cometer o erro de defini-los: conceber o amor em sua transversalidade, ao mesmo tempo, sútil e densa, e a presença deste como possibilidade de ação política do professor em sua existência humana. O texto parte de uma contextualização sobre a noção de amor mundi para, posteriormente, apresentar ressonâncias destas ideias na formação e exercício da docência. Insere a formação de educadores em uma abordagem complexa e multirreferencial, situada nos atravessamentos de fluxos de permanência e de emergência, das experiências humanamente temporalizadas, para sugerir que sejam fundadas novas éticas amorosas que respeitem as liberdades dos processos de subjetivação. Por fim, coloca o amor mundi, de Arendt, como um convite a fazer um exercício, mais do que de reflexão, de incursão ativa na vida, tendo a abertura para o amor ao mundo, em suas múltiplas aparências e maneiras de expressão, como uma possibilidade de empreendimento de novas formas de educar, que potencializem relações plurais e solidárias ao mundo comum.
\end{abstract}

Palavras-chave: Amor. Docência. Educação. Formação de professores.

\section{Algumas considerações iniciais}

Estamos vivenciando um tempo de coexistências que é atravessado, ininterruptamente, pelos encontros entre fluxos de permanência e fluxos de emergência. Os fluxos de permanência indicam os saberes e crenças secularmente construídos que povoam os atravessamentos históricos, mas que não são cristalizados e nem desconectados da contemporaneidade; os fluxos de emergência referem-se aos novos saberes e crenças que surgem aliados às permanências históricas. Tais fluxos ocorrem nas experiências humanamente temporalizadas que acontecem no tempo cronológico, todavia, em seus movimentos, não há um antes e um depois isolados, um passado e um futuro dissipados, mas um entre: o presente, em constante, atualização. (ALMEIDA, 2017) Desse modo, ambos coexistem nas temporalidades humanas, em uma dialógica processual de atualizações, potencializações, virtualizações, homogeneizações, heterogeneizações. (GALEFFI; SALES, 2012) Os movimentos desses fluxos são infinitos, comunicantes e se dobram uns nos outros, pois

\footnotetext{
1 Versão revisada e modificada do texto publicado, originalmente, nos Anais do II Seminário Internacional de
} Filosofia, Poética e Educação, realizado na Universidade Federal de Juiz de Fora, Minas Gerais, Brasil, 2015.

Verônica Domingues Almeida Universidade Federal da Bahia veedomingues@gmail.com 
eles provocam pulsações que geram, entre outras coisas, as formas abertas - aparências e maneiras - de concebermos a existência.

No encontro incessante desses fluxos, a temporalidade atual, que se alimenta vorazmente das relações criadas pelas tecnologias e é centrada na produção e no consumo, mas que também se compreende como período de transição e é assumidamente pluralista e multifacetado, sugere a emersão de temáticas já debatidas, questionadas e classificadas por saberes da ciência moderna, com a finalidade de tensionar a rigidez imposta pelo paradigma arborrescente em sua busca pela captura de uma verdade única. A emergência de algumas temáticas, como a do amor, por exemplo, revela tentativas de, no movimento dos fluxos, construir novos referenciais em uma linguagem múltipla, complexa e aberta a diferenciadas possibilidades de compreensão dos fenômenos próprios da contemporaneidade.

O tema do amor, assunto de interesse desde a História e Filosofia clássicas até a ciência moderna, perpassando pela Biologia, Psicologia, Linguística, Arte, Filosofia, Teologia e tantas outras áreas dos saberes tradicionais, assim como, dos saberes não 1egitimados pela ciência, como o mito, a crença e o conhecimento popular, possui um amplo construto conceitual, já percebido em seu caráter multidisciplinar. Contudo, muitas vezes, apesar de ser estudado por diferentes campos, fica limitado ao diálogo uníssono e restrito de cada um deles e, assim, é destroçado, cabendo a cada área a posse da classificação a que o tema se permite fazer, como por exemplo, reação hormonal, condição psicológica das paixões, ação caridosa e estritamente fraternal, desejo, entre tantas outras concepções possíveis. Porém, esse afeto, que nos faz humanos em nossa humanidade, não pode ser restrito a compreensões lineares que, mesmo quando horizontalizadas, se fazem retas. Amor é sentimento com movimentos infindáveis. É polimorfo, polissêmico, polilógico. É da mundanidade da vida, portanto, múltiplo, incerto e inescrutável.

Dessa maneira, entendo que compreender o amor, em diferentes dimensões e possibilidades não pode ser um exercício uníssono, pois a própria palavra possui em sua etimologia um caráter polissêmico e complexo que dá origem a significados múltiplos, díspares e contrastantes, tanto na linguagem comum, quanto na tradição filosófica. (ABBAGNANO, 2012) Sendo assim, compreender aspectos de concepções de amor a fim de propor um diálogo 
com a formação de professores, implica em buscar fundamentos multirreferenciais e complexos nessas redes de saberes, expressas pela intercomunicação entre os conhecimentos mítico, sagrado, popular e literário, entre outros, e, ainda, entre os conhecimentos construídos por diferentes áreas como a Psicologia, a Sociologia, a Linguística, a Biologia, a Filosofia, a Arte e a própria Pedagogia, por exemplo. Para estudar o amor é preciso este olhar múltiplo, pois "o amor é qualquer coisa de <um >, como uma tapeçaria que é tecida de fios extremamente diversos e de origens diferentes". (MORIN, 1997, p. 18)

A ideia do estudo sobre a concepção de amor mundi em Hannah Arendt partiu, justamente, da necessidade de compreender o amor em sua faceta de profunda transversalidade e de íntima pertinência com os temas das relações sociais e da formação humana. O amor ao mundo anunciado por Arendt, se apresenta como uma possibilidade fecunda de entender o tema do amor a partir do modo como ele pode existir nos atos, nas coisas e na forma como nos relacionamos com o mundo, sem necessariamente destacá-lo como apenas forma e/ou conteúdo e, sim, na sua solúvel apresentação sob diferentes modos de conceber as relações humanas nos processos formativos. Diante destas conjecturas iniciais, pretendo, neste ensaio, propor um diálogo entre o amor mundi em Hannah Arendt e as possíveis ressonâncias dele na formação e no exercício da docência.

\section{Amor como fenômeno de compartilhamento do mundo}

O amor não foi sistematicamente abordado por Hannah Arendt em seus estudos, contudo, podemos destacar em suas produções trechos e articulações que provocam a emergência da compreensão polilógica deste tema. Arendt não fez do amor um conteúdo coisificado; ela tratou da existência humana e da vida no mundo, nas condições de sobrevivência, produção e ato. Na condição de ação, o amor surge diluído, porém constantemente reportado e, por isso, pode ser considerado um conceito central de sua obra.

Arendt deu início aos estudos sobre o amor no doutorado, com a escrita da tese intitulada: O conceito de amor em Santo Agostinho: ensaio de uma interpretação filosófica (1929). Nesta fase, a referida autora contrapôs a ideia de amor como natureza, com a ideia de amor como devir da vontade humana. Seus estudos agostinianos the aproximaram de conceitos como nascimento e morte e ao en- 
tendimento destes, como fundantes para a compreensão da vida na Terra, assim como, the apresentaram a noção de amor mundi. Todavia, o tema do amor não se restringiu a tese e perpassou toda a produção de Arendt no decorrer da vida, inicialmente, a partir da problematização sobre as argumentações hierárquicas do amor, postas por Agostinho, e, posteriormente, a partir da reelaboração da noção de amor mundi para além da dimensão apolítica de abnegação, traduzindo-a para a ordem da ação.

Nos diálogos com Agostinho, Arendt apresentou em sua tese, a distinção do amor em três categorias: o desejo; o amor na relação entre o homem e o Deus criador; e o amor ao próximo ou a vida em sociedade. Nestas proposições ela se permitiu dialogar com o teólogo/filósofo e questionar algumas disposições por ele postas quanto as ideias de amor, de vida e de existência no mundo.

Quanto ao amor relacionado ao desejo e à cobiça e o amor caridoso, ela apontou o princípio da transitoriedade humana para demonstrar a diferenciação entre o amor do desejo e da ausência e o amor fraternal. Na tese, Arendt coloca que os bens nascem e morrem independentemente do homem, que a eles está ligado pelo desejo, desse modo, se nenhum bem, pessoa ou ser é infinito, o amor por medo da ausência não pode ser considerado amor e, sim, cobiça. (ARENDT, 1997) Já o amor que aspira a fraternidade e a felicidade, indicado por Agostinho como amor puro, é considerado fraterno e voltado para a abnegação das coisas mundanas, como uma proposta para a eternização da vida, através da intervenção divina. Desse modo, ela expôs que, para Agostinho, na medida em que a cobiça escraviza o homem em seus desejos e no medo da perda, a caridade o liberta, por se construir como a busca pela eternidade, pela garantia de um futuro. Nas palavras de Arendt (1997, p. 25):

Caridade e cobiça diferenciam-se pelo objeto que visam e não pelo como do próprio visar. Descrevem desde logo a pertença a qualquer coisa e não à atitude, o habitus. O homem é aquilo que se esforça por atingir. O amor é a mediação entre o que ama e aquilo que ama; o que ama nunca está isolado daquilo que ama, isso the pertence. O desejo daquilo que é a ordem do mundo é mundano, pertence ao mundo. O que cobiça decidiu ele próprio, através da sua cobiça, a sua corruptibilidade, enquanto a caridade, visto que tende para a eternidade, torna-se ela própria eterna. Se é verdade que todo o homem particular vive isolado, ele tenta no entanto ultrapassar sempre este isolamento através 
do amor; mas também não é menos verdade que a cobiça faça dele um habitante deste mundo ou que a caridade o obrigue a viver num futuro absoluto, mundo que ele habitará.

O texto de Arendt provoca questionamentos sobre a transitoriedade da vida. Como poderia existir o amor para além da busca da matéria? Poderia existir amor para além da cobiça? Como pode ser o amor da caridade? Em Agostinho há a proposição de que amor caridoso seja o retorno do ser humano para si mesmo, quando, assim, encontra Deus.

Efetivamente, o que é que se quer dizer com falar de si mesmo através de ti, senão aprender a conhecer-se a si mesmo? E eu procuro-te fora de mim, e não encontro o Deus do meu coração. Pois Ele estava dentro e eu fora. Em seguida, exortado a regressar a mim mesmo, penetrei no meu próprio interior, sob Tua condução; e isso foi-me possível por que Tu vieste ajudar-me. (AGOSTINHO apud ARENDT, 1997, p. 29)

Essas proposições agostinianas contribuíram fortemente para a formação do pensamento e da fé cristã na cultura ocidental. A ideia de Deus dentro de cada ser humano, remeteu a formação espiritual voltada para a vida eterna e para a crença na necessidade de um amor caridoso. A vida finita faz do ser humano um ente transitório que alimenta-se da fé, para não temer a morte, e ama, com a finalidade de manutenção da vida, no patamar da crença na eternidade. Como coloca Arendt (1997, p. 95):

A morte, que só ela, excetuando Deus, tem o poder de subtrair o homem ao mundo, reenvia à eleição no seio do mundo. Teme-se a morte porque se ama o mundo (amor mundi); a morte aniquila não só qualquer posse do mundo, mas também todo o desejo de amar qualquer coisa por vir que se espera do mundo. A morte destrói a relação natural no mundo da qual o amor mundi é a expressão. Por isso, a morte é de modo puramente negativo, de tal maneira poderosa, separando-nos do mundo, como o amor de que se apodera em Deus o próprio ser.

Arendt problematiza a renúncia, própria do amor caridoso, tendo em vista que na tese, ela contrapõe o pensamento de Agostinho quanto a ideia do amor ser proposto e disposto para divindade. Assim, também, faz com o amor ao próximo, que é colocado por Agostinho como vinculado ao nascimento, indicando uma ação 
solidária ao outro com vistas a vida eterna, pois o nascer de um novo ente é entendido como a renovação da fé e a salvação através do amor mútuo, da caridade e da fraternidade. A vida vivida no coletivo e a criação dos vínculos humanos, na tradução de Agostinho, enfatizam a nossa condição transitória de ser, entre o nascimento e a morte, pois a vida é compreendida como uma passagem e o mundo como transitório, ou seja, entre o nascimento e a morte está uma passagem para a eternidade, na qual devemos viver em comunhão solidária para o seu alcance. Essas proposições retiram do amor a sua mundanidade, transportando-o como veículo divino para o alcance da vida eterna, o que para Arendt leva o ser ao isolamento. Para ela, se a máxima cristã "ama o próximo como a si mesmo" tem por referência o amor à Deus, "[...] o amor ao próximo, enquanto mandamento de renunciar a si, nunca permite compreender como é que pode haver aí ainda um próximo para a criatura absolutamente isolada." (ARENDT, 1997, p. 114). Assim, a divindade se sobrepõe às relações entre os homens, caracterizando o amor como desinteresse pela mundanidade e oferecendo a divindade os poderes que determinam a vida através da morte.

A proposição do amor como a busca pela eternidade, retira da ação humana seu potencial criador e anula o nascimento como advento da vida, fatorando à morte os propósitos da existência, pois nesta concepção, o Deus, ser supremo, nos encaminha a negar o mundo, em prol da eternização da vida. Destarte, o amor neste contexto é apolítico e até antipolítico (ARENDT, 2010) na medida em que está restrito ao âmbito da intimidade e impede a ação, desfavorecendo os interesses do homem pela vida mundana, em prol da busca pela eternidade. Contudo, sobre quando Agostinho propõe que o mundo é amado enquanto é criado e que quando o ser humano ama o mundo, ama a Deus, pois Deus é o mundo criado por cada ser humano em si mesmo, Arendt expõe que este amor a si que é ao mundo, é a realização do amor ao próximo, pois neste amor ao próximo, não é exatamente o próximo que é amado, mas o próprio amor. (ARENDT, 1997)

Inicialmente, o amor em Arendt aparece alinhavado aos diálogos com Agostinho, porém, no decorrer da construção de sua obra, a ideia do amor foi sendo ampliada e passou a ressoar em tons mais complexos e ambíguos. Nos questionamentos da tese, o amor aparece fortemente arraigado às ideias cristãs de peregrinação e de abnegação do mundo em prol da eternidade, mas, ao longo da vida, 
Arendt o ressignifica passando a disseminar o amor mundi como o respeito pelo legado das gerações precedentes com o desejo de que o mundo se constitua no espaço de convivência livre e plural, isto é, como um espaço eminentemente humano e humanizante. (ALMEIDA, 2011) A ideia de amor mundi surge então, como uma noção que propõe uma espécie de partilha discursiva entre os seres humanos em convivência no mundo, desde o nascimento até a morte. "[...] O mundo comum reúne-nos na companhia uns dos outros e, contudo, evita que colidamos uns com os outros" (ARENDT, 2010, p. 62), portanto, o amor mundi, ou amor ao/no mundo, reafirma que a convivência "significa essencialmente ter um mundo de coisas interposto entre os que nele habitam, como uma mesa se interpõe entre os que se assentam ao seu redor; pois, como todo intermediário, o mundo ao mesmo tempo separa e estabelece uma relação entre os homens". (ARENDT, 2010, p. 62) Esta relação seria, portanto, voltada para a responsabilidade que assumimos com o mundo e com a chegada dos novos neste espaço, que é antigo e novo ao mesmo tempo.

O estudo apresentado em O conceito de amor em Santo Agostinho pertence a uma fase bem determinada da juventude de Hannah Arendt e que traz, também, algumas das referências carregadas pela autora em seu íntimo pensar, voltadas para as marcas e para as contradições entre a inspiração cristã e o judaísmo e pelo próprio movimento dos fluxos de permanência e emergência da temporalidade em que foi elaborado. As relações conflituosas entre as ideias de amor como a busca de si em si/divino e como o amar o mundo com o outro, propôs ao mesmo tempo uma aproximação e um distanciamento dos escritos de Agostinho, em especial, em relação a noção de amor mundi. No entanto, como coloca Duarte (2003, p. 4),

[...] o que aí se afirma sobre esse conceito só pode ser aplicado de maneira esclarecedora em relação à sua reflexão política madura, se o conceito de amor mundi for descontextualizado e adaptado para propósitos políticos estranhos aos do pensamento agostiniano, num procedimento teórico que é típico das violentas apropriações por meio das quais Arendt estabeleceu seu diálogo com os grandes pensadores da tradição filosófica ocidental. 
Como visto, ela inicia seus estudos buscando compreender o amor agostiniano e, em seguida, promove uma mutação no conceito de amor mundi destacando a relevância política deste, como pertença e compartilhamento do mundo, não o negando, assim, em seus escritos sobre o totalitarismo, a aniquilação da singularidade humana, a massificação da sociedade e as atividades da condição humana, por exemplo. Dessa forma, podemos dizer que Arendt retrata uma reconstrução da noção de amor mundi como o signo de seu próprio pensamento político. "Nem liberal, nem marxista, nem conservador, o traço característico do pensamento arendtiano pode ser definido como o Amor Mundi, o 'amor do mundo', em que o genitivo tem o sentido de 'por amor ao mundo' ou 'amor pelo mundo'". (DUARTE, 2003, p. 3)

Ao falar de existência humana no mundo Arendt pouco se concentrou na educação, todavia, como tratou da vida ativa em uma dimensão política da construção de um mundo comum, Arendt trouxe em seu bojo, também solúvel como o amor, o cerne desta temática. As suas proposições com o tema, discorrem sobre a ação política de apresentação do mundo preexistente aos novos seres recém-chegados. Com isto, está posto o desafio de não apenas ensiná-los a abraçar o que é dado, mas de reinventar e renovar o mundo como está posto. (ALMEIDA, 2011) Para tanto, é preciso que a educação se proponha a contagiar os novos com o amor mundi, compreendendo-o como fenômeno de compartilhamento do mundo.

\section{Formação de professores: o amor mundi e a profissão}

Ao tratar de amor e educação, para não incorrer em psicologismos e/ou pedagogismos, é necessário compreender a formação docente como complexa e multirreferencial. Os princípios epistemológicos da complexidade e da multirreferencialidade atuam em oposição a busca da "verdade universal" aspirada pelo pensamento disjuntor, dogmático e instrumental da ciência moderna. Portanto, tais referenciais são acionados em contraposição a um pensamento higienista, linear, ortodoxo e totalizante, já que tratam de fluxos, incompletudes, imperfeições e desordens, imbuídas "simultaneamente de verdades e não verdades". (MORIN, 2007, p. 97) e que "não se curvam a reducionismos". (BORBA, 1998, p. 13) Estes pressupostos contribuem para a ampliação do entendimento 
de formação para além de uma finalidade pautada em simplismos técnicos e homogeneismos conceituais, pois contribuem com a inclusão das dimensões da pluralidade e da heterogeneidade, já que abarcam diferentes ângulos e negam os reducionismos propostos pelas concepções clássicas.

Entender a atividade formativa em uma abordagem complexa e multirreferencial, implica, portanto, em uma formação sensível, pensada como processo que envolve as experiências acontecidas nos percursos de vida cada docente [...]. Destarte, a compreensão da complexidade da prática pedagógica demanda em uma formação que não se restrinja à acadêmica, envolvendo o desenvolvimento pessoal, estético, cultural, profissional, político, didático e organizacional da profissão docente, ou seja, incorre na necessidade de uma postura multirreferencial. (CANDA; ALMEIDA, 2018)

Desse modo, aspectos existenciais sobre o modo como o ser humano cria e recria os acontecimentos de/em sua vida precisam ser elementos considerados no escopo formativo docente, inclusive, aspectos sensíveis, como o amor.

Para Arendt o trabalho, a obra e a ação são atividades que condicionam a existência humana, porém, nem mesmo a vida - a natalidade, a mortalidade - podem nos determinar de modo inteiro, pois jamais somos condicionados de modo absoluto. (ARENDT, 2010) Ao afirmar que não é possível sermos "programados" integralmente, Hannah contribui com o distanciamento da ideia de formação como dispositivo puramente técnico ligado a uma vivência do ser humano na Terra como homo faber. Destarte, ela traz o amor ao mundo como interface subjacente a existência e como elemento de compreensão da vida activa, pois, mesmo como fator que se relaciona à sobrevivência e à produção, está para além do necessário e do útil, ao gerar, através da inquietude e do engajamento ativo com o mundo, a possibilidade de liberdade. A partir dessa gama conceitual é possível afirmar que a discussão do amor na formação docente precisa se situar no atravessamento dos fluxos de permanência e emergência e, de modo complexo e multirreferencial, abarcar a multiplicidade de significações que o amor possui como ato-conceito. Isso, para que não sirva como veículo de conformação - (en)formação, (de)formação - e, sim, 
como instrumento de ação em prol da constituição de uma vida activa cada vez mais plural e plena no planeta.

O imaginário ortodoxo dominante define o amor como elemento restrito a seara das virtudes, dos sentimentos e emoções, afastando-o da dimensão política que Hannah Arendt traz, com propriedade, em sua obra. Os pensamentos da filósofa traduzem a necessidade de pensar e de agir em direção ao entendimento dos fenômenos do mundo contemporâneo, fazendo emergir o amor como fio condutor da sua compreensão da existência humana nesse mundo, de modo plural. Como dito, a educação e o amor não receberam atenção direcionada nas obras de Arendt, mas no escopo de seu pensamento eles são previstos como elementos fundantes da existência. Ela aposta na esperança de que o ser humano nasce, não para morrer, mas para começar seu processo de vida em um mundo plural e coletivo, composto e construído por si e pelo outro. "Arendt poderia dizer que o amor mundi é a nossa opção de pertencer ao mundo - ao que acrescentaria que hoje essa pertença deixou de ser uma simples escolha e tornou-se muito mais uma questão e um desafio". (ALMEIDA, 2011, p. 80)

O tratado de Arendt em muito pode contribuir para o entendimento das revelações de amor ao mundo exercitados na atividade transformadora da ação docente. Em seu ensaio A crise na educação Arendt, explicitamente, cita o amor mundi como possibilidade educativa de responsabilidade com o mundo. Ela propõe que:

A educação é assim o ponto em que se decide se se ama suficientemente o mundo para assumir responsabilidade por ele […]. A educação é também o lugar em que se decide se se amam suficientemente as nossas crianças para não as expulsar do nosso mundo deixando-as entregues a si próprias, para não lhes retirar a possibilidade de realizar qualquer coisa de novo, qualquer coisa que não tínhamos previsto, para, ao invés, antecipadamente as preparar para a tarefa de renovação de um mundo comum. (ARENDT, 2005, p. 14)

Diante desta perspectiva, a ação docente precisa estar imbuída de um pensamento político e implicada com a renovação do mundo. A educação não deve apenas ajudar a promover a reconciliação do ser humano com o mundo como este está posto, no campo das injustiças e das negações. Mais do que uma reconciliação, são necessárias a reinvenção e a reconstrução deste mundo. Para isso, 
a educação precisa contagiar os novos com o amor e ser compreendida como formação comprometida com o mundo comum, no qual, assim esperamos, os alunos possam encontrar o seu lugar. (ALMEIDA, 2011) Propondo uma ampliação dessas proposições, penso que, através da educação, o amor mundi também deve contagiar os adultos e, neste caso, destaco os professores, seres em constante e intencional formação. Considero que é preciso que o tema do amor seja posto em pauta para que estes profissionais, em suas práticas, possam se reconhecer em uma perspectiva de renovação e se sentir contemplados em suas ações políticas de amor ao mundo. Pois, como "a educação não pode abrir mão do amor ao mundo e às crianças" (ALMEIDA, 2011, p. 16), ela também não pode abrir mão do amor, em sua dimensão política, na formação docente.

Destas enunciações surgem alguns questionamentos: o amor, seja como proposto por Arendt, em sua filosofia plural e política, ou ainda, como posto no ideário que o relega ao sacerdócio e a abnegação, tem espaço na educação contemporânea? Na sociedade da vida líquida (BAUMAN, 2005) há espaço para a compreensão do amor nas relações educativas? É uma questão de permissão ou o amor/amor mundi se revela existencial nas relações humanas, independente da intencionalidade?

Tais questionamentos nos levam a crer que, nos atravessamentos dos fluxos de permanência e de emergência, a ideia do amor pode ser contemplada em infinitas significações, pois os sentidos construídos partem das subjetividades dos sujeitos, envolvem a idealização do perfil profissional aos longos dos tempos, o cultivo da imagem docente e constituem referências para reprodução de crenças e de valores que regem a prática pedagógica dos educadores. Portanto, os discursos de amor expressos na prática pedagógica podem revelar o mundo da cotidianidade, do imaginário e do simbólico entre o prescrito, o vivido e o inventado, no processo de constituição das subjetivações de cada docente em sua existência.

Compreender a presença do amor na formação de professores se faz importante tendo em vista as relações entre as contingências, as singularidades e a professoralidade docente. (PEREIRA, 2013) A desvalorização do magistério, as más condições de trabalho, o ideário da educação como salvadora do mundo e do professor como o veículo desse salvamento, podem constar das ideias de amor que os educadores apresentam em suas narrativas existenciais. Os 
discursos de amor, ao longo da história, vêm imprimindo a ideia de docência como missão e sacerdócio, por exemplo, e o papel político do educador acaba sendo relegado a outras dimensões, excluindo o amor como uma possibilidade de ação política. Dialogar com o amor mundi de Arendt é uma proposta de reflexão sobre tais questões, pois a partir de uma posição política de negociação coletiva e plural, é possível promover um embate frente ao desmoronamento da formação docente e às polaridades de posturas "amorentes" dispostas pela sociedade da aniquilação da pluralidade humana. Todavia, esta mesma sociedade abre espaço para o debate, a reconstituição e a ressignificação de conceitos emergentes como este, possibilitando, de modo mais aberto ao complexo e ao multirreferencial, uma compreensão do amor e de suas relações com a educação e com a formação de professores.

Como Arendt não tratou de formular, diretamente, em seu discurso político e filosófico, os meandros das relações educativas para a construção e manutenção das existências no mundo coletivo, a leitura arendtiana de Almeida (2011, p. 89, grifos da autora), traz uma colaboração importante para anunciar algumas possibilidades do amor mundi na educação:

Em face a destruição do mundo e de tudo que nos servirá de parâmetro para nos mover nele, muda a 'acentuação' do amor mundi. Mais do que abraçar o que é dado, ele precisa se reconciliar como o mundo que permitiu e permite barbaridades, e, mais do que dar continuidade precisa, sobretudo, renovar ou refundar. Reconciliação e renovação do mundo, dizem respeito as atividades do pensamento e da ação. O ponto decisivo é que, embora o mundo esteja em crise, nós, em princípio, não perdemos as capacidades de pensar e de agir, não obstante tenhamos de pensar sem a orientação e o apoio de uma tradição ilesa e nossa ação dependa cada vez mais de nossa capacidade de iniciar algo novo impensável. Se aqueles que constantemente chegam ao mundo se engajarão nesses desafios, depende, ao menos em parte, de que na educação consigamos contagiá-los com o amor mundi.

Neste espectro, os esforços pedagógicos se transferem da ideia do que para a ideia de quem e a formação humana deixa de ser voltada, exclusivamente, para a construção de conhecimentos se colocando aberta para a construção de relações plurais. A ação educativa não é individualista e solitária, ela só é possível nas relações 
entre as pessoas e essa dimensão coletiva demanda uma postura política de imersão social e um posicionamento situado quanto à necessidade de pensarmos o mundo para além de utilitarismos, concebendo-o como espaço comum deste momento e de momentos futuros, vividos pelas novas gerações. (ALMEIDA, 2017) Portanto, o amor compreeendido como fenômeno de compartilhamento de mundo, ao contagiar docentes, em sua formação, tenderá, assim esperamos, a contagiar os alunos com o compromisso de uma convivência mais aberta, solidária e plural no/com o planeta.

\section{Por novas éticas amorosas na educação}

Propor um diálogo entre a concepção de amor mundi em Arendt e a formação de professores poderá contribuir para revelar facetas da compreensão do mundo em seus espaços comuns e em suas práticas de segregação. É conveniente falar de amor mundano para propor o impensável, isto é, a construção de novas éticas amorosas para a educação, mas, ao mesmo tempo, é um risco, levando em conta a brutal crise civilizatória que vivemos, exposta no cenário crasso de desigualdades sociais em que o planeta está mergulhado e que explode em muitas mãos, inclusive, nas mãos dos professores, nos seios das escolas. É importante buscar possibilidades interpretativas dessas searas, com a finalidade de contribuir para um debate cada vez mais próximo da formação do ser coletivo, para a sua existência em um mundo comum e plural, no qual as singularidades poderão ser preservadas sem reservas, ao mesmo tempo em que, o individualismo e a negação do coletivo tendem a ser combatidas.

Estudar o amor e propor um diálogo no/do mundo com a educação, tendo o cuidado de anunciar sentidos sem cometer o erro de defini-los, foi, portanto, o desafio proposto: conceber o amor em sua transversalidade, ao mesmo tempo, sútil e densa e sua presença como possibilidade de ação política do professor em sua existência humana. A proposta de tratar de amor e docência se coloca, neste instante, como possibilidade de tensionar a formação de professores, a prática educacional, os dispositivos pedagógicos e a condição de atuação docente no Brasil, visando a se constituir em um convite, para que fiquemos atentos aos barulhos dos processos de expansão e contração vibráteis do amor, que ressoam nas paisagens da educação e com isso criemos novas éticas amorosas, 
abertas e plurais. Neste escopo, o amor mundi de Arendt nos convida a fazer esse exercício, mais do que de reflexão, de incursão ativa na vida. Neste contexto, é que a abertura para o amor ao mundo, em suas múltiplas aparências e maneiras de expressão, pode ser engendrada como possibilidade de empreendimento de novas formas de educar, que potencializem relações plurais.

Sugerir novas éticas amorosas para a educação, empreendidas em relações plurais, não se refere a uma proposta que vise, exclusivamente, a relação biunívoca de convivência com os outros, mas, mais do que isso, educar as relações para lidar com o conhecimento, com o mundo e consigo mesmo. Uma educação para as relações não funciona sobre um saber-poder a priori, pois volta-se para as potencialidades e as atualizações. Refere-se a capacidade de aprendermos as relações das coisas entre si, entre elas e o mundo e entre nós mesmos, indistinta e concomitantemente. Implica em pensar o ato pedagógico nas múltiplas e infinitas redes que se constroem e se destroem entre os fenômenos, não apenas tratando da questão do "porquê" ou do "como", mas evidenciando as conexões imensuráveis. (ALMEIDA, 2017) Promover a atividade educativa para as relações com o saber, com o mundo, com o outro e consigo mesmo, não se apresenta como um otimismo de insondável ingenuidade, a partir da instituição de uma mediação metodológica para o domínio da consciência, mas, sim, como possibilidade de abertura aos processos de subjetivação livres, que engendramos em nossa existência. Não tem um objetivo previsto e nem um destino a ser alcançado, acontece na atitude de amor ao mundo, em uma perspectiva de cooperação e reciprocidade.

\title{
Love, teaching and Hannah Arendt: one dialogue proposed in/around the world
}

\begin{abstract}
This essay webs considerations towards the concept of Amor mundi, since the suggestions of Hanna Arendt and the teacher training. The challenge was proposed, through the love, to propose a dialogue in the/of world with the education, announcing senses, without make the mistake of define them: to conceive the love into their transversality, at the same time, smooth and dense; and the presence of this like possibility of political action of the teacher in their human existence. The text starts from a contextualization about the notion of amor mundi to, later, present resonances of those ideas in the teacher training and in exercise. Including the training of educators into a complex and multireferential approach. Situated in the cross-linking of permanency flows and of emergency of experiences humanly temporized, to suggest that will be founded new love ethics respecting the freedoms of the subjectivation process. At last puts the Arentd's amor mundi, as an invi-
\end{abstract}


tation to make an exercise, more than reflexion, of active incursion, having the opening to the love to world, in their multiple appearances and form of expression, as a possibility of enterprising of new ways to educate, that empower relationships plurals and solidary to the common world.

Key-Words: Education. Love. Teaching. Teacher training.

\title{
Amor, enseñanza y Hannah Arendt: uno diálogo propuesto en/por el mundo
}

\begin{abstract}
RESUMEN: Este ensayo teje consideraciones al respecto del concepto de amor mundi, a partir de lo sugerido por Hanna Arendt, y la formación docente. El desafío propuesto se coloca, a través del amor, proponer un diálogo en el/ del mundo con la educación, anunciando sentidos, sin cometer el error de definirlos: concebir el amor en su transversalidad, al mismo tiempo, sutil y densa, y la presencia de este como posibilidad de acción política del profesor en su existencia humana. El texto parte de una contextualización sobre la noción del amor mundi para, posteriormente, presentar resonancias de esas ideas en la formación y ejercicio de la docencia. Incluye la formación de educadores en un abordaje complejo y multireferencial, situado en los entrecruzamientos de flujos de permanencia y de emergencia de las experiencias humanamente temporalizadas, para sugerir que sean fundadas nuevas éticas amorosas que respeten las libertades de los procesos de subjetivación. Por fin coloca el amor mundi, de Arendt, como una invitación a hacer un ejercicio, más que de reflexión, de incursión activa en la vida, teniendo la apertura para el amor al mundo, en sus múltiples apariencias y maneras de expresión, como una posibilidad de emprendimiento de nuevas formas de educar, que potencialicen relaciones plurales y solidarias al mundo común.
\end{abstract}

Palabras clave: Amor. Docencia. Educación. Formación de Profesores.

\section{Referências}

ABBAGNANO, Nicola. Dicionário de filosofia. Tradução Alfredo Bossi e Ivone Castilho. 6. ed. São Paulo: Martins Fontes, 2012.

ALMEIDA, Domingues Verônica. Poli[AMOR]fia: paisagens da docência. 2017. Tese (Doutorado em Educação) - Faculdade de Educação, Universidade Federal da Bahia, Salvador, 2017. Disponível em: https:// repositorio.ufba.br/ri/handle/ri/24776 Acesso em: 7 jul. 2020.

ALMEIDA, Sievers Vanessa. Educação em Hannah Arendt: entre o mundo deserto e o amor ao mundo. São Paulo: Cortez, 2011.

ARENDT, Hannah. O conceito de amor em Santo Agostinho. Tradução Alberto Pereira Dinis. Lisboa: Instituto Piaget, 1997.

ARENDT, Hanna. Entre o passado e o futuro. Tradução Mauro W. Barbosa de Almeida. 5. ed. São Paulo: Perspectiva, 2005.

ARENDT, Hannah. A condição humana. Tradução Roberto Raposo. 11. ed. Rio de Janeiro: Forense, 2010. 
BAUMAN, Zygmunt. Vida líquida. Tradução Carlos Alberto Medeiros. Rio de Janeiro: Jorge Zahar Editor. 2005.

BORBA, Sérgio. Aspectos do conceito de multirreferencialidade nas ciências e nos espaços de formação. In: BARBOSA, Joaquim (org). Reflexões em torno da abordagem multirreferencial. São Carlos: Edufscar, 1998. p. 35-55.

CANDA, Nascimento Cilene; ALMEIDA, Domingues Verônica. Arte e saberes sensíveis na formação e prática da docência. Revista LES, Teresina, Ano 23, n. 39, maio/ago., 2018. Disponível em: https:// revistas.ufpi.br/index.php/lingedusoc/article/view/7965. Acesso em: 7 jul. 2020.

DUARTE, André. Hannah Arendt e o pensamento político sob o signo do amor mundi. In: YUNES, Eliana (org.). Mulheres de palavras. São Paulo: Edições Loyola, 2003.

GALEFFI, Dante; SALES, Kathia Marise Borges. Tudo que é real é virtual. Tudo que é virtual é real: considerações sobre a temporalidade mediada. In: ARNOUD, Soares de Lima Júnior (org.). Educação e contemporaneidade: contexto e singularidades. Salvador: Edufba: Eduneb, 2012. p. 103-124.

MORIN, Edgar. Amor, poesia e sabedoria. Tradução Ana Paula de Viveiros. Lisboa: Instituto Piaget, 1997.

MORIN, Edgard. Introdução ao pensamento complexo. 3. ed. Porto Alegre: Sulina, 2007.

PEREIRA, Marcos Vilela. Estética da professoralidade: um estudo crítico sobre a formação do professor. Santa Maria, RS: EdUFSM, 2013.

Submetido em 15/04/2019. Aceito em 18/02/2020. 